this. Upon a clean slip of tinned iron, place one or two drops of the suspected material, and hold it over a spirit lamp: the fluid will speedily evaporate, leaving. if the process be arrested at that point, scarcely a trace upon the metallic surface. Continue the application of heat; in a few moments after the desiceation is complete, a spot of an inch or so in dianneter, over which the drop had spread with the first ebullition, will gradually assume a rich reddish-brown color, with a brilliant lustre, as if coated with a film of rarnish or Japan lacquer. A stronger heat produces a darker color, but the lustre continues till the heat becomes sufficiently intense to decompose the substance. This experiment has succeeded perfectly in my hands, when the urine on trial, previously known to contain glucose, was of specific gravity less than 1030 , and still further reduced by the addition of three or four times as much of water. It is thus proved to be a delicate test. I suppose it to be conclusive, also, for I have never yet found any other constituent of urine, normal or abnormal, capable of producing anything at all like the same appearance under the same treatment. The nearest approach is this: some samples of urine not diabetic, when treated in this way, leave a faint, dull, yellowish stain, easily distinguished from caramel by its paler color, and the entire absence of lustre. I need scarcely add, that a solution of sugar, not diabetic, exhibits almost exactly the same reaction.

With the augmented interest attached to glucosuria, since, besides being a leading feature of a most intractable, but fortunately rare, discase, it is found symptomatically associated with several other diseases and injuries, an increased facility for its detection is almost a necessity of the profession. I trust they will find it in the simple and beautiful experiment above described.

Middlefield, Nov. 12, 1860.

\title{
SIR BENJAMIN BRODIE ON THE USE AND ABUSE OF TOBACCO.
}

THE opinions of this distinguished physiologist and surgeon on the keenly-debated subject of the influences, sanitary and social, of tobacco smoking, have been expressed in the following interesting letter to the Times:-

"Sir,-Having been applied to, some time since, to join in a petition to the House of Commons, that they would appoint a committee to inquire into the effects produced by the prevailing habit of tobacco smoking, I declined to do so; first, because it did not appear to me that such a committee would be very competent to discuss a question of this kind; and, secondly, because, even if they were so, I did not see that it would be possible for Parliament to follow up by any act of legislation the conclusions at which they might have arrived. Nevertheless, I am ready to admit that the subject is one of no trifing importance, and woll worthy the seri- 
ous consideration of any one who takes au interest in the present and future well-being of society. From these considerations it is that I now venture to address to you the following observations.

"The empyreumatic oil of tobacco is produced by distillation of that herb at a temperature above that of boiling water. One or two drops of this oil (according to the size of the animal) placed on the tongue, will kill a cat in the course of a ferw minutes. A certain quantity of the oil must be always circulating in the blood of an habitual smoker, and we cannot suppose that the effects of it on the system can be merely negative. Still, I am not prepared to subscribe to the opinion of those who hold that, under all circumstances, and to howerer moderate an extent it be practised, the smoking of tobacco is prejudicial. The first effect of it is to soothe and tranquillize the nervous system. It allays the pains of hunger, and relieves the uneasy feelings produced by mental and bodily exhaustion. To the soldier who has passed the night in the trenches before a beleaguered town, with only a distant prospect of breakfast when the morning has arrived; to the sailor, contending with the elements in a storm; to the laborer, after a hard day's work; to the traveller in an uncultivated region, with an insufficient supply of food, the use of a cigar or a tobacco pipe may be not only a grateful indulgence, but really benenicial. But the occasional use of it under such circumstances is a very different matter from the habit of constant smoking which prevails in certain classes of society at the present day. The effects of this habit are, indeed, various, the difference depending on difference of constitution, and difference in the mode of life otherwise. But, from the best observations which $I$ have been able to make on the subject, I am led to believe that there are very few who do not suffer harm from it, to a greater or less extent. The earliest symptoms are manifested in the derangement of the nervous system. $\Lambda$ large proportion of habitual smokers are rendered lazy and listless, indisposed to bodily and incapable of much mental exertion. Others suffer from depression of the spirits, amounting. to hypochondriasis, which smoking relieves for a time, though it aggravates the evil afterwards. Occasionally there is a general nervous excitability, which, though very much less in degree, partakes of the nature of the delirium tremens of drunkards. I have known many individuals to suffer from severe nervous pains, sometimes in one, sometimes in another part of the body. Almost the worst case of neuralgia that ever came under my observation, was that of a gentleman who consulted the late Dr. Bright and myself. The pains were universal, and never absent; but during the night they were especially intense, so as almost wholly to prevent sleep. Neither the patient himself nor his medical attendant had any doubts that the disease was to be attributed to his former habit of smoking, on the discontinuance of which he slowly and gradually recovered. An eminent surgeon, who has a great experience in 
ophthalmic diseases, belicres that, in some instances, he has been able to trace blindness from amaurosis to excess in tobacco smoking; the connection of the two being pretty well established in one case by the fact that, on the practice being left off, the sight of the patient was gradually restorel. It would be easy for ine to refer to other symptoms indicating the deficient power of the nervous system to which smokers arc liable: but it is unnecessary for me to do so; and, indecd, there are some which I would rather leave them to imagine for themselves than undertake the descrip. tion of them nysself in writing.

"But the ill effects of tobacco are not confined to the nervous system. In many instances there is a loss of the liealthy appetite for food, the inperfect state of the digestion being soon rendered manifest by the loss of flesh and the sallow countenance. It is difficult to say what other diseases may not follow the imperfect assimilation of food continued during a long period of time. So many causes are in operation in the human body which may tend, in a greater or less degree, to the production of orgauic changes in it, that it is only in some instances we can venture to pronounce as to the precise manner in which a disease that proves mortal has originated. From cases, however, that have fallen under my own observation, and from a consideration of all the circumstances, I cannot entertain a doubt that, if we could obtain accurate statistics on the subject, we should find that the value of life in inveterate smokers is considerably below the average. Nor is this opinion in any degree contradicted by the fact that there are individuals who, in spite of the inhalation of tobacco smoke, live to be old, and without any material derangement of the health; analogous exceptions to the general rule being met with in the cases of those who have indulged too freely in the use of spirituous and fermented liquors. In the carly part of the present century, tobacco smoking was almost wholly confined to what are commonly called the lower grades of society. It was only every now and then that any one who wished to be considered as a gentleman was addicted to it. But since the war on the Spanish Peninsula, and the consequent substitution of the cigar for the tobacco-pipe, the case has been entirely altered. The greatest smokers at the present time are to be found, not among those who live by their bodily labor, but among those who are more advantageously situated, who have better opportunities of education, and of whom we have a right to expect that they should constitute the most intelligent and thoughtful members of the community. Nor is the practice confined to grown-up men. Boys, even at the best schools, get the habit of smoking, because they think it manly and fashionable to do so; not unfrequently because they have the example set them by their tutors, and partly because there is no friendly voice to warn them as to the special ill consequences to which it may

VoL. LXIII. - $17^{* *}$ 
give rise where the process of growth is not jet completed, and the organs are not yet fully developed.

"The foregoing observations relate to the habit of smoking as it exists amongst us at the present time. But a still graver question remains to be considered. What will be the result if this habit be continued by future generations? It is but too true that the sins of the fathers are visited upon their children and their children's children. We may here take warning fiom the fate of the Red Indians of America. An intelligent American physician gives the following explanation of the gradual extinction of this remarkable people:-One generation of them became addicted to the use of the fire-water. They have a degenerate and compara. tively imbecile progeny, who indulge in the same ricious habit with their parents. Their progeny is still more degenerate, and after a very few generations the race ccases altogether. We may also take warning from the history of another nation, who some few centuries agro, while following the banners of Solyman the Magnificent, were the terror of Christendom, but who, since then, having become more addicted to tobacco-smoking than any of the European nations, are now the lazy and lethargic Turks, held in contempt by all civilized communities. In thus placing together the consequences of intemperance in the use of alcohol and that in the use of tobacco, I should be sorry to be misunderstood as regarding these two kinds of intemperance to be in an equal degree pernicious and degrading. The inveterate tobacco-smoker may be stupid and lazy, and the habit to which he is addicted may gradually tend to shorten his life and detcriorate his offspring, but the dram-drinker is quarrelsome, mischicrous, and often criminal. It is under the influence of gin that the burglar and murderer become fitted for the task they have undertaken. The best thing that can be said of dram-drinking is, that it induces disease, which carries the poor wretch prematurely to the grare, and rids the world of the nuisance. But, unfortunately, in this, as in many other cases, what is wanting in quality is made up in quantity. There are checks on one of these evil habits which there are not on the other. The dram-drinker, or, to use a more general term, the drunkard, is held to be a noxious animal. He is an outcast from all decent society, while there is no such exclusion for the most assiduous smoker. The comparison of the effects of tobacco with those of alcohol leads to the consideration of a much wider question than that with which I set out. In all ages of .which we have any record, mankind have been in the habit of resorting to the use of certain vegetable productions, not as contributing to nourishment, but on account of their having some peculiar influence as stimulants or sedatives (or in some other way) on the nerrous system. Tobacco, alcohol, the Indian liemp, the kava of the South Sea Islanders, the Paraguay tea, coffee, and even 
tea, belong to this category. $\Lambda$ disposition so unirersal may almost be regarded as an instinct, and there is sufficient reason to believe that, within certain limits, the indulgence of the instinct is useful. But we must not abuse our instincts. This is one of the most important rules which man, as a responsilule being, both for his own sake and that of others, is bound to obserre. Even such moderate agents as tea and coffec, taken in excess, are prejudicial. How much more so are tobacco and alcohol, tending, as they do, not only to the degradation of the individual, but to that of future generations of our species? If tobacco smokers would limit themselves to the occasional indulgence of their appetite, they would do little harm to themselves or others; but there is always danger that a sensual habit once begun may be carried to exeess, and that danger is never so great as in the case of those who are not compelled by the necessities of their situation to be actively employed. For such persons the prudent course is to abstain from smoking altogether. Trusting that you and your readers will ex. cuse me for having occupied so large a space in your columns,-I am, sir, your obedient servant,

B. C. Brodie."

\section{Zieports of Jterital Societies.}

EXTRACTS FRON THE RECORDS OF TIE BOSTON SOCIETY FOR MEDICAL IMPROVEMENT. BY FRANCIS MINOT, M.D., SECRETARY.

Ocr. 8th.-Cancer of the Foot in a Child. Dr. Mortand exhibited the patient, and also three colored drawings of the part affected, which were made three months since, and then accurately represented the disease.*

The patient is a boy, six years old, of Irish parentage, always rather delicate, with marked pigeon-chest, yet, before the accident upon which the present disease followed, active, lively, and functionally well. He was first seen by Dr. M. at the Central Office of the Dispensary, and had been previously attended by Dr. Joln W. Sawyer, one of the Visiting Physicians.

About a year ago, he received a severe kick, from a schoolmate with whom he was playing, upon the inside of the right foot. He suffered a good deal of pain at the time, and was disabled for a day or two, but scemingly had then recovered from the effects of the blow. After a few weeks, however, he began to have pain in the injured part, and the latter began gradually to enlarge. The pain became sharp and lancinating, shooting up the leg; and he was often kept awake by it at night. He grew very slowly, and his appetite was capricious; yet he did not lose flesh, nor has lis digestion been disturbed. The swelling of the part has slowly, but steadily increased, and now in. volves most of the inner aspect, and sole, of the foot, and has sent off a protuberance towards the rear, just above the os calcis. The veins are very much dilated, and, in several portions of the tumor, strong

- These were executed by Mr. R. D. Wilkie, 20 Knoelaud Street. 